\title{
ИССЛЕДОВАНИЕ ПОКАЗАТЕЛЕЙ КАЧЕСТВА МАКАРОННЫХ ИЗДЕЛИЙ ИЗ ПОЛБЫ*
}

\author{
O.F. Fazullina, S.O. Smirnov, A.A. Korolev
}

\section{THE RESEARCH OF QUALITY INDICATORS OF PASTA FROM SPELT}

Фазуллина Олия Фанавиевна - канд. техн. наук, ст. науч. сотр. отдела пищевых концентратов и оборудования НИИ пищеконцентратной промышленности и специальной пищевой технологии - филиала ФИЦ питания, биотехнологии и безопасности пищи, Московская обл., Ленинский p-н, пос. Измайлово.

E-mail: olfazullina@yandex.ru

Смирнов Станислав Олегович - канд. техн. наук, зам. директора по научной работе НИИ пищеконцентратной промышленности и специальной пищевой технологии - филиала ФИЦ питания, биотехнологии и безопасности пищи, Московская обл., Ленинский р-н, пос. Измайлово.

E-mail: sts_76@bk.ru

Королев Алексей Александрович - канд. техн. наук, зав. отделом пищевых концентратов и оборудования НИИ пищеконцентратной промышленности и специальной пищевой технологии - филиала ФИЦ питания, биотехнологии и безопасности пищи, Московская обл., Ленинский p-н, пос. Измайлово. E-mail: korleh@mail.ru

Цель исследования - разработка рецептур и технологии производства макаронных изделий из нетрадиционных компонентов для диетического профилактического и диетического лечебного питания при избыточном весе или ожирении для расширения ассортимента обогащенных продуктов с пониженной калорийностью. Работа проведена в НИИ пищеконцентратной промьшленности и специальной пищевой технологии - фрилиал ФГБУН «ФИЦ питания, биотехнологии и безопасности пищи» (Московская область). Использовались мука полбяная цельнозерновая (ООО «Гарнещ», Рос-
Fazullina Oliya Fanavievna - Cand. Techn. Sci., Senior Staff Scientist, Department of Food Concentrates and Equipment, Research and Development Institute of Food Concentrates Industry and Special Food Technology - FRC Branch of Nutrition, Biotechnology and Safety of Food, Moscow Region, Leninsky District, S. Izmailovo. E-mail: olfazullina@yandex.ru

Smirnov Stanislav Olegovich - Cand. Techn. Sci., Deputy Director on Scientific Work, Research and Development Institute of Food Concentrates Industry and Special Food Technology - FRC Branch of Nutrition, Biotechnology and Safety of Food, Moscow Region, Leninsky District, S. Izmailovo.

E-mail: sts_76@bk.ru

Korolev Alexey Alexandrovich - Cand. Techn. Sci., Head, Research and Development Institute of Food Concentrates Industry and Special Food Technology - FRC Branch of Nutrition, Biotechnology and Safety of Food, Moscow Region, Leninsky District, S. Izmailovo.

E-mail: korleh@mail.ru

сия, по ТУ 9293-014-89751414-11), мука гречневая (000 «Гарнещ», Россия, по ТУ 9293-00243175543-03), овощные порошки (брокколи, сельдерей) низкотемпературной сушки ("GreenFood Organic», Россия), соевая клетчатка (Россия), яичный порошок (Россия), макаронное тесто, макаронные изделия. Отбор проб, определение цвета, формы, вкуса, запаха, сохранности фрормы сваренных макаронных изделий, количества сухого вещества, перешедшего в варочную воду, производился по ГОСТ 31964-2012 «Изделия макаронные. Правила приемки и методы определения качест-

* Исследование выполнено в рамках Программы Фундаментальных научных исследований государственных академий наук (тема № 0529-2019-0065 «Разработка и оценка эфффективности новых инновационных пищевых конщентратов и продуктов диетического профилактического питания для спецконтингентов»). 
ва». При проведении исследований анализы выполнены в 3-кратной повторности. Результаты выражены в виде средних арифрметических значений по стандартным методикам. Изготовлены опытные образцы макаронных изделий типа вермишели на лабораторном макаронном прессе Sandore (модель Sandorina) (Италия). Применили средний mun замеса теста с влажностью 31 \%. По органолептическим и фозико-химическим показателям, варочным свойствам полученные макаронные изделия отвечают требованиям нормативной документации. Использование нетрадиционного сырья не оказало отрицательного влияния на показатели качества готовых изделий и состояние после варки. Проведенным исследованием доказана возможность выработки макаронной продукции по разработанным рецептурам с хорошим качеством, соответствующим требованиям действующей нормативной документации. Использование в рецептуре нетрадиционного сырья не требует изменений технологического процесса или замены традиционного оборудования, а также позволяет обогатить макаронную продукцию белком, клетчаткой, витаминами, минеральными веществами. Производство макаронных изделий из муки полбы, овощных порошков расширяет ассортимент продуктов диетического лечебного и диетического профрилактического питания.

Ключевые слова: макаронные изделия, полба, овощные порошки, рецептура, технология, качество, калорийность.

The research objective was the development of recipes and production technology of pasta from nonconventional components for dietary preventive and dietary medical foods at the excess weight or obesity for expansion of the range of enriched products with lowered caloric content. The research was carried out in Scientific Research Institute of Food-Concentrate Industry and Special Food Technology - Branch of FSBI "FRC of Nutrition and Biotechnology" (Moscow region). Whole grain spelt flour, buckwheat flour, broccoli and celery powders, soy fiber were used in the research. Spelt flour wholegrain (JSC 'Garnets', Russia, on TC 9293014-89751414-11), flour buckwheat (JSC 'Garnets',
Russia, on TC 9293-002-43175543-03), vegetable powders (broccoli, celery) of low-temperature drying ("GreenFood Organic", Russia), soy cellulose (Russia), egg powder (Russia), macaroni dough, pasta were used. The sampling, determination of color, form, taste, smell, safety of the form of cooked pasta, the amounts of the solid which passed into cooking water were made in accordance with State Standard 31964-2012 "Pasta. Acceptance procedures and quality determination methods". When carrying out the researches the analyses were made in 3-fold frequency. The results were expressed as arithmetic averages of the values by standard techniques. The prototypes of pasta like vermicelli on a laboratory macaroni press of Sandore (Sandorina model) were made (Italy). Applied average type of a batch of dough was with humidity of $31 \%$. Received pasta met organoleptic and physical and chemical indicators, cooking properties the requirements of standard documentation. Using of nonconventional raw materials had no negative impact on indicators of quality of finished products and a state after cooking. The possibility of development of macaroni production on the developed compoundings with high quality was proved to relevant requirements of existing standard documentation by conducted research. Using in the compounding of nonconventional raw materials does not demand any changes of technological process or replacement of traditional equipment, and also allows enriching macaroni production with protein, cellulose, vitamins and mineral substances. The production of pasta from pelt flour, vegetable powders expands the range of the products of dietary medical and dietary preventive foods.

Keywords: pasta, spelt, vegetable powders, recipe, technology, quality, caloric content.

Введение. Разработка и производство продуктов питания различных товарных групп с функциональными свойствами является одним из самых перспективных направлений пищевой отрасли. Исследования в этом направлении проводятся отечественными [1-4] и зарубежными учеными [5-7].

Макаронная продукция имеет стабильно большой спрос у населения всех стран, поэтому перспективна как объект для внесения обогащающих добавок и использования нетрадици- 
онного сырья [1, 2, 5-7]. Расширение сырьевой базы для макаронного производства способствует повышению пищевой ценности, снижению калорийности и расширению ассортимента продуктов диетического лечебного и диетического профилактического питания для различных групп населения.

Отечественные макаронные предприятия работают в основном на хлебопекарной муке изза недостаточного количества специальной макаронной муки, которую получают из сортов твердой пшеницы. Макаронные изделия, выработанные из хлебопекарной муки, имеют высокую калорийность и невысокую пищевую ценность. Поэтому хлебопекарную муку для макаронного производства обогащают всевозможными добавками [1, 2, 8, 9]. Оптимизация количественного и качественного состава рецептур по содержанию белков, жиров, углеводов, витаминов, минералов, а также разумное снижение калорийности является одним из путей нормализации веса $[8,9]$.

В нашем исследовании при составлении рецептуры макаронных изделий решалась задача снижения калорийности и повышении содержания пищевых волокон, витаминов и минеральных веществ. В опубликованных ранее работах представлены результаты исследований по разработке рецептур макаронных изделий из муки полбы с добавлением овощных порошков $[8,9]$. Полба - низкокалорийный злак, превосходящий пшеницу по содержанию белка, ненасыщенных жирных кислот, пищевых волокон, витаминов группы B, железа [1]. Полба рекомендуется в диетах при избыточном весе и ожирении - достаточно распространенной проблеме на сегодня, так как содержит вещества, нормализующие жировой обмен $[1,8,9]$. Гречневая мука характеризуется высокой степенью сбалансированности белков, высоким содержанием витаминов, клетчатки. Включение в рецептуру гречневой муки обогатит продукт растительным белком, витаминами, незаменимыми аминокислотами, минеральными веществами [2]. Брокколи и сельдерей, как и все овощи, богаты клетчаткой, пектинами, витаминами, минеральными веществами, органическими кислотами, натуральными красителями, различными биологически активными веществами. Добавление в макаронное тесто овощных компонентов упроч- няет его структуру, снижает адгезию, улучшает технологические характеристики, облегчает процесс производства макаронных изделий, улучшает показатели качества готовых изделий: внешний вид, состояние поверхности, цвет $[8,9]$. И, что немаловажно, придает готовым макаронным изделиям фуннциональные свойства.

Использование в макаронном производстве нетрадиционного сырья изменяет свойства теста и готовых макаронных изделий. Поэтому при разработке новых рецептур проводится комплекс исследований.

Цель исследования: изучение возможности совместного использования муки полбяной цельнозерновой, муки гречневой, порошков брокколи, сельдерея в производстве макаронных изделий.

Задачи исследования: изучение органолептических и физико-химических показателей качества лабораторных образцов макаронных изделий и их варочных свойств.

Материалы и методы исследования. Использовались мука полбяная цельнозерновая (ООО «Гарнец», Россия, по ТУ 9293-01489751414-11), мука гречневая (ООО «Гарнец», Россия, по ТУ 9293-002-43175543-03), овощные порошки (брокколи, сельдерей) низкотемпературной сушки («GreenFood Organic», Россия), соевая клетчатка (Россия), яичный порошок (Россия), макаронное тесто, макаронные изделия.

Отбор проб, определение цвета, формы, вкуса, запаха, сохранности формы сваренных макаронных изделий, количества сухого вещества, перешедшего в варочную воду, проводились по ГОСТ 31964-2012 «Изделия макаронные. Правила приемки и методы определения качества».

При проведении исследования анализы выполнены в 3-кратной повторности. Результаты выражены в виде средних арифмметических значений по стандартным методикам.

Результаты исследования и их обсуждение. Исследование проведено в лабораториях ГНУ НИИ ПП и СПТ - филиал ФГБУН «ФИЦ питания и биотехнологии» и Центра реологии пищевых сред НИИ хлебопекарной промышленности. Изготовлены лабораторные образцы с различными процентными соотношениями рецептурных компонентов макаронного теста. За ос- 
нову приняли традиционную рецептуру макаронных изделий.

Для исследования были изготовлены 4 опытных образца макаронных изделий типа вермишели на лабораторном макаронном пресce Sandore (модель Sandorina) (Италия). Применили средний тип замеса теста с влажностью $31 \%$.

Образец 1 - мука полбяная цельнозерновая $100 \%$.

Образец 2 - мука полбяная цельнозерновая 60 \% и мука гречневая $40 \%$.

Образец 3 - мука полбяная цельнозерновая и 4 \% порошка брокколи.

Образец 4 - мука полбяная цельнозерновая и 4 \% порошка сельдерея.
На выходе из матрицы полуфабрикат макаронных изделий сохранял форму, не прилипал к инструментам и оборудованию, не крошился, имел однородный цвет.

При резке и раскладке изделия не крошились и сохраняли придаваемую им форму, были пластичными. Как было отмечено в работах [1, 2, 8, 9], пластичность теста связана с суммарным количеством в рецептурных компонентах белка, клетчатки, пектина, имеющих высокую водопоглотительную способность. Пластичность важна при определении режимов сушки макаронных полуфабрикатов для исключения потемнения, усадки, растрескивания [1, 2]. Внешний вид сухих и отваренных макаронных изделий представлен на рисунке.

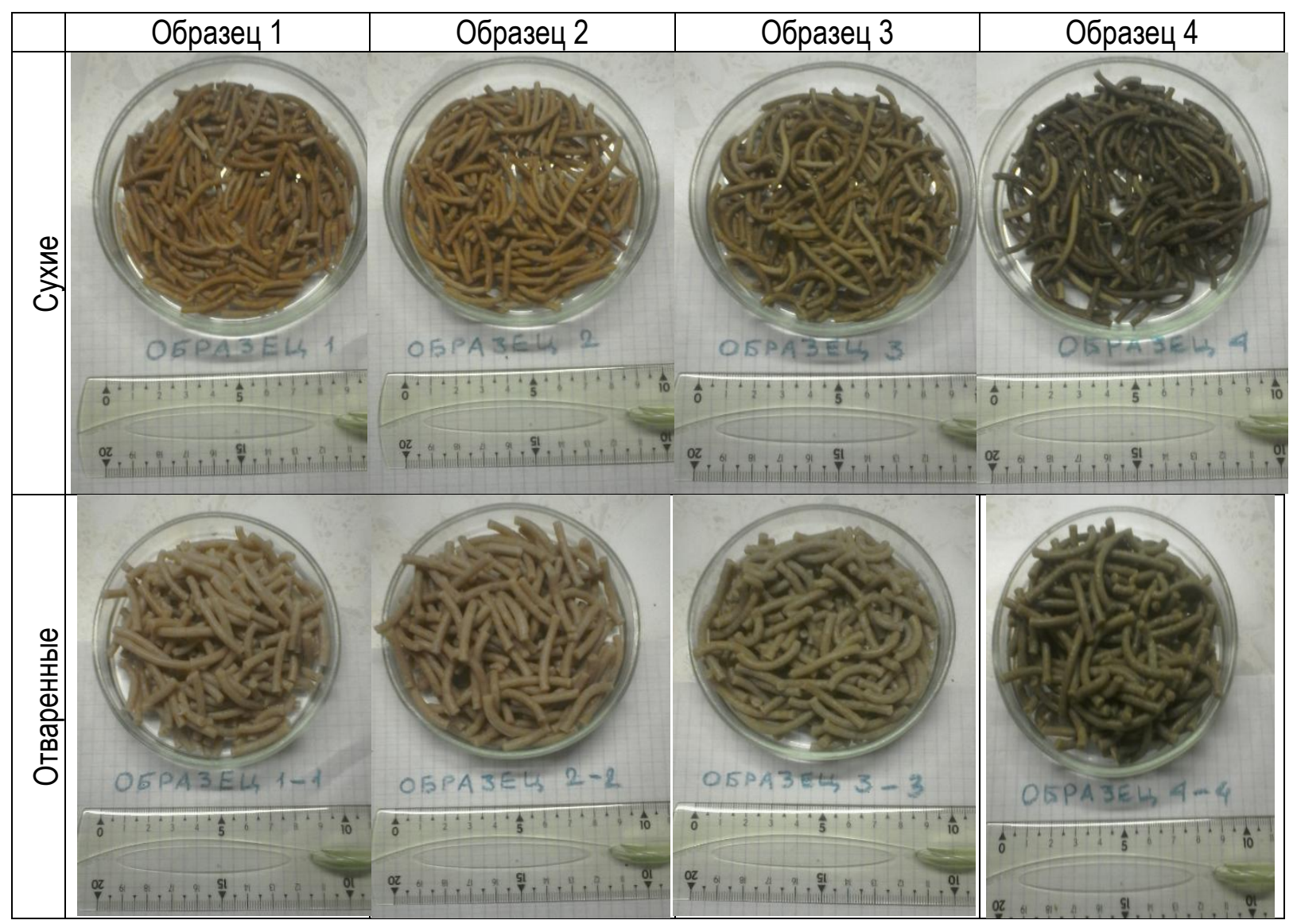

Внешний вид сухих и отваренных макаронных изделий

Сухие макаронные изделия, в зависимости от использования добавок, отличались по цвету. В процессе варки изделия частично обесцвечиваются. Отваренные образцы характеризовались ровным цветом с кремовым оттенком (образцы 1 и 2) и зеленоватым оттенком (образцы 3 и 4), приятным вкусом и запахом, свойствен- ным макаронным изделиям и используемому сырью. После варки не слипались, сохранность формы для всех образцов 100 \%. Варочная вода была прозрачной. Потери сухих веществ составили 2,1-3,3\%, что отвечает требованиям ГОСТ 31743-2012 «Изделия макаронные. Общие технические условия» (не более 6 \%). Ко- 
эфффициент увеличения объема после варки имел следующие значения: образец 1 - 1,97; образец 2 - 1,98; образец 3 - 1,99; образец 4 2,07 . Макаронные изделия хорошего качества должны иметь значения коэффициента в пределах 1,5-2,5. Полученные значения коэффи- циента увеличения объема соответствуют указанному диапазону значений. Полученные изделия оценены как изделия хорошего качества.

Результаты исследований органолептических, физико-химических показателей и варочных свойств образцов представлены в таблице.

\section{Органолептические, физико-химические показатели качества}

\begin{tabular}{|c|c|c|c|c|}
\hline \multirow[b]{2}{*}{ Показатель } & \multicolumn{4}{|c|}{ Исследованный образец } \\
\hline & $\begin{array}{c}\text { Образец } 1 \\
\text { (полба) }\end{array}$ & $\begin{array}{l}\text { Образец } 2 \\
\text { (гречка) }\end{array}$ & $\begin{array}{l}\text { Образец } 3 \\
\text { (с брокколи) }\end{array}$ & $\begin{array}{c}\text { Образец } 4 \\
\text { (с сельдереем) }\end{array}$ \\
\hline Цвет & $\begin{array}{r}\text { Однотонный с } \\
\text { без слег }\end{array}$ & $\begin{array}{l}\text { зым оттенком, } \\
\text { ромеса }\end{array}$ & $\begin{array}{r}\text { Однотонный с } 3 \\
\text { без сле }\end{array}$ & $\begin{array}{l}\text { оватым оттенком, } \\
\text { епромеса }\end{array}$ \\
\hline $\begin{array}{l}\text { Состояние } \\
\text { поверхности }\end{array}$ & \multicolumn{4}{|c|}{ Гладкая, без шероховатостей } \\
\hline Излом & \multicolumn{4}{|c|}{ Мучнистый } \\
\hline Форма & \multicolumn{4}{|c|}{ Соответствующая типу изделий } \\
\hline Вкус & \multicolumn{4}{|c|}{$\begin{array}{c}\text { Свойственный данному изделию, со своеобразным приятным привкусом } \\
\text { используемых компонентов }\end{array}$} \\
\hline Запах & \multicolumn{4}{|c|}{$\begin{array}{c}\text { Свойственный данному изделию, с легким своеобразным запахом, не портя- } \\
\text { щим изделий }\end{array}$} \\
\hline $\begin{array}{l}\text { Состояние } \\
\text { изделий после } \\
\text { варки }\end{array}$ & \multicolumn{4}{|c|}{ Не слипаются } \\
\hline $\begin{array}{l}\text { Сохранность } \\
\text { формы сварен- } \\
\text { ных изделий, \% }\end{array}$ & \multicolumn{4}{|c|}{100} \\
\hline $\begin{array}{l}\text { Сухое вещест- } \\
\text { во, перешед- } \\
\text { шее в варочную } \\
\text { среду, \% }\end{array}$ & 2,1 & 2,5 & 3,2 & 3,3 \\
\hline
\end{tabular}

Bсе образцы имели мучнистый излом, что объясняется тем, что при работе лабораторного макаронного пресса не было стадии вакуумирования. При использовании макаронного пресса с вакуумированием этот недостаток устраняется.

Исследования будут продолжены.

Выводы. Проведенными исследованиями доказана возможность выработки макаронной продукции по предложенным рецептурам с хорошим качеством, соответствующим требованиям действующей нормативной документации. Использование нетрадиционного сырья не оказало отрицательного влияния на показатели качества готовых изделий и состояние после варки.

\section{Литература}

1. Малютина Т.Н., Туренко В.Ю. Исследование влияния нетрадиционного вида муки на качество макаронных изделий из мягкой пшеницы // Вестн. ВГУИТ. - 2016. - № 4. C. 166-171.

2. Федорова Р.А., Волков В.С., Новикова В.Ю. Разработка рецептуры и технологии макаронных изделий с добавлением гречневой муки // Изв. Санкт-Петербургского гос. аграр. ун-та. - 2017. - № 1 (46) - С. 91-95.

3. Санжаровская Н.С., Сокол Н.В., Храпко О.П. Использование нетрадиционного сырья в технологии сырцовых пряников // Вестн. КрасГАУ. - 2018. - № 1 (136). - С. 147-154.

4. Типсина Н.Н., Самитина Г.Г. Разработка мучных кондитерских изделий для здорового питания с применением кабачкового пю- 
ре // Вестн. КрасГАУ. - 2018. - № 2 (137). C. 144-149.

5. Singh J., Kaur S., Rasane P. Evaluation of the Nutritional and Quality Characteristics of Black Carrot Fortified Instant Noodles // Current Nutrition and Food Science, 2018, vol. 14, pp. 18. DOI: https://doi.org/10.2174/157340131 3666170724115548.

6. Silva, Maria Luiza Tonetto, Brinques, Graziela Brusch, \& Gurak, Poliana Deyse (2019). Utilização de farinha de subproduto de brotos para elaboração de massa alimentícia fresca. Brazilian Journal of Food Technology, 22, e2018063. Epub 21 de mar o de 2019. - URL: https://dx.doi.org/10.1590/1981-6723.06318/.

7. Paiva, Caroline Liboreiro, Queiroz, Valéria Aparecida Vieira, \& Garcia, Maria Aparecida Vieira Teixeira (2019). Características tecnológicas, sensoriais e químicas de massas secas sem glúten à base de farinhas de sorgo e milho // Brazilian Journal of Food Technology, 22, e2018095. Epub 25 de abril de 2019.

8. Смирнов С.О., Фазуллина О.Ф. Использование нетрадиционного сырья в производстве макаронных изделий повышенной пищевой ценности // Техника и технология пищевых производств. - 2019. - Т. 49, № 3. - C. 454-469. - DOI: 10.21603/20749414-2019-3-454-469.

9. Фазуллина О.Ф., Смирнов С.О. Макаронные изделия повышенной пищевой ценности с использованием полбы // Ползуновский вестник. - 2019. - № 3. - C. 13-19. - DOI: 10.25712/ASTU.2072-8921.2019.03.003.

\section{Literatura}

1. Malyutina T.N., Turenko V.Yu. Issledovanie vliyaniya netradicionnogo vida muki na kachestvo makaronnyh izdelij iz myagkoj pshenicy // Vestn. VGUIT. - 2016. - № 4. S. 166-171.

2. Fedorova R.A., Volkov V.S., Novikova V.Yu. Razrabotka receptury i tekhnologii makaronnyh izdelij s dobavleniem grechnevoj muki // Izv. Sankt-Peterburgskogo gos. agrar. un-ta. - 2017. - № 1 (46) - S. 91-95.

3. Sanzharovskaya N.S., Sokol N.V., Hrapko O.P. Ispol'zovanie netradicionnogo syr'ya $\mathrm{V}$ tekhnologii syrcovyh pryanikov // Vestn. KrasGAU. - 2018. - № 1 (136). - C. 147-154.

4. Tipsina N.N., Samitina G.G. Razrabotka muchnyh konditerskih izdelij dlya zdorovogo pitaniya s primeneniem kabachkovogo pyure // Vestn. KrasGAU. - 2018. - № 2 (137). C. 144-149.

5. Singh J., Kaur S., Rasane P. Evaluation of the Nutritional and Quality Characteristics of Black Carrot Fortified Instant Noodles // Current Nutrition and Food Science, 2018, vol. 14, pp. 18. DOI: https://doi.org/10.2174/157340131 3666170724115548.

6. Silva, Maria Luiza Tonetto, Brinques, Graziela Brusch, \& Gurak, Poliana Deyse (2019). Utilização de farinha de subproduto de brotos para elaboração de massa alimentícia fresca. Brazilian Journal of Food Technology, 22, e2018063. Epub 21 de mar o de 2019. - URL: https://dx.doi.org/10.1590/1981-6723.06318/

7. Paiva, Caroline Liboreiro, Queiroz, Valéria Aparecida Vieira, \& Garcia, Maria Aparecida Vieira Teixeira (2019). Características tecnológicas, sensoriais e químicas de massas secas sem glúten à base de farinhas de sorgo e milho // Brazilian Journal of Food Technology, 22, e2018095. Epub 25 de abril de 2019.

8. Smirnov S.O., Fazullina O.F. Ispol'zovanie netradicionnogo syr'ya $\mathrm{V}$ proizvodstve makaronnyh izdelij povyshennoj pishchevoj cennosti // Tekhnika i tekhnologiya pishchevyh proizvodstv. - 2019. - T. 49, № 3. - S. 454469. - DOI: 10.21603/2074-9414-2019-3-454469.

9. Fazullina O.F., Smirnov S.O. Makaronnye izdeliya povyshennoj pishchevoj cennosti $\mathrm{s}$ ispol'zovaniem polby // Polzunovskij vestnik. 2019. - № 3. - S. 13-19. - DOI: 10.25712/ASTU.2072-8921.2019.03.003. 